\title{
Are Sore Throat Patients Who Hope for Antibiotics Actually Asking for Pain Relief?
}

\author{
Mieke L. van Driel, $M D, M S c^{1}$ \\ An De Sutter, MD, PbD ${ }^{1}$ \\ Myriam Devengele, $M A, P b D^{1}$ \\ Wim Peersman, $M A^{2}$ \\ Christopher C. Butler, MD, PbD \\ Marc De Meyere, $M D, P b D^{1}$ \\ Jan De Maeseneer, $M D, P b D^{1}$ \\ Thierry Christiaens, $M D, P^{3} D^{3}$ \\ 'Department of General Practice and \\ Primary Health Care, Ghent University, \\ Ghent, Belgium \\ ${ }^{2}$ Department of General Practice, Centre \\ for Health Services Research, Cardiff \\ University, Cardiff, UK \\ ${ }^{3}$ Department of Physical Therapy, \\ Artevelde Hogeschool, Ghent, Belgium
}

AC Annals Journal Club selection; see inside back cover or http://www. annfammed.org/AJC/.

Conflicts of interest: none reported

\section{CORRESPONDING AUTHOR}

Mieke L. van Driel, MD, MSc Department of General Practice and Primary Health Care

Ghent University

De Pintelaan 185

UZ-1K3, B-9000 Ghent, Belgium

mieke.vandriel@ugent.be

\begin{abstract}
PURPOSE Antibiotics are still overprescribed for self-limiting upper respiratory tract infections such as acute sore throat, and physicians mention patient's desire for antibiotics as a driving force. We studied patients' concerns when visiting their family physician for acute sore throat, more specifically the importance they attach to antibiotic treatment and pain relief.
\end{abstract}

METHODS Family physicians in 6 peer groups in Belgium participated in an observational postvisit questionnaire survey. Patients aged 12 years and older making an office visit for acute sore throat were invited to indicate the importance of different reasons for the visit.

RESULTS Sixty-eight family physicians provided data from 298 patients. The 3 most frequently endorsed reasons for visiting the physician were examination to establish the cause of the symptoms, pain relief, and information on the course of the disease. Hopes for an antibiotic ranked 11th of 13 items. Patients who considered antibiotics very/rather important valued pain relief significantly more than patients who considered them little/not important $(P<.001)$. Patients who hoped for antibiotics felt more unwell $(P<.001)$, had more faith in antibiotics to speed recovery $(P<.001)$, and were less convinced that sore throat was a self-limiting disease $(P<.012)$. A multivariate model, adjusted for age, sex, and educational status, showed that the desire for pain relief is a strong predictor of the hope to receive a prescription for antibiotics.

CONCLUSION Our study suggests that patients with acute sore throat and who hope for antibiotics may in fact want treatment for pain. Trials are needed to test whether exploring patients' expectations about pain management and offering adequate analgesia can assist physicians in managing sore throats without prescribing antibiotics.

Ann Fam Med 2007:4:494-499. DOI: 10.1370/afm.609.

\section{INTRODUCTION}

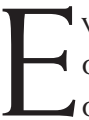
vidence-based guidelines on the management of acute sore throat, or pharyngitis, in primary care point to the self-limiting nature of the condition and recommend restricted use of antibiotics. ${ }^{1-4}$ Even so, antibiotics are still often prescribed for acute sore throat. This unnecessary prescribing adds to the burden of antibiotics consumed in the community, which is a driver of antimicrobial resistance. ${ }^{5}$ In Belgium more than $50 \%$ of patients in primary care complaining of a sore throat receive an antibiotic. ${ }^{6}$ Antibiotic prescribing for upper respiratory tract infections is related to a defensive attitude of the family physician. ${ }^{7}$ Doctors feeling pressured by their patients to prescribe an antibiotic is an important factor that leads to overprescribing. ${ }^{8-11}$ Several studies have shown, however, that patients' expectations are often not made explicit during the office visit ${ }^{13}$ and correlate poorly with the physician's perceptions of these expectations. ${ }^{14-16}$ Nevertheless, physicians are 10 times more likely to prescribe an antibiotic if they perceive patients expect an antibiotic prescription. $8,10,17$ While doctors focus on whether to prescribe 
an antibiotic, patients, including those expecting an antibiotic, might have other concerns. It is possible that patients erroneously believe that antibiotics are the best way of dealing with their main concern. As a result, physician and patient become entangled in an implicit web of misunderstandings that may be an important barrier in the implementation of guidelines on appropriate antibiotic use. Addressing these beliefs and providing more appropriate treatment may help clinicians treat these patients without prescribing an antibiotic. The aim of our study was to assess what patients consider important when they see their family physician for an acute sore throat and to search for clues that may be useful in understanding and managing their hope for an antibiotic prescription.

\section{METHODS}

\section{Patients and Setting}

Six local peer groups of family physicians were randomly selected from a total of 169 eligible groups in 2 Belgian provinces. These groups of 8 to 25 family physicians meet at least 4 times yearly to discuss items aimed at improving quality of patient care. All 6 peer groups agreed to participate in a cross-sectional questionnaire survey. During a 6-week period from May 2002 to September 2002, participating physicians were asked to invite consecutive unaccompanied patients aged 12 years and older whose main reason for a visit was an acute sore throat to participate. By recruiting patients during the office visit through their family physician, those visiting for other reasons (eg, common cold) could be excluded. Patients filled out the questionnaire in the waiting room immediately after the office visit and deposited the anonymous coded and sealed questionnaires in a box provided by the researchers. The questionnaires were confidential, and the physicians did not have access to the contents.

\section{Measurements}

Patients were asked to rate the importance of 13 reasons for visiting their family physician on a 4 -point Likert scale (very, rather, little, or not important). The list included 8 items from a validated questionnaire. ${ }^{18,19}$ The remaining 5 items were selected by an expert group of 6 family physicians on the basis of their relevance to our study question: an item referring to pain relief ("I want Dr to give me something for the pain"), an explicit wish for an antibiotic, a request for an attestation to justify legitimate absence from work or school, a wish for explanation of possible treatments, and a wish for information on expected illness duration. In addition, patients were asked to rate the severity of their disease on a $100-\mathrm{mm}$ visual analogue scale. Knowledge and beliefs about acute sore throat and the use of antibiotics were scored using a validated questionnaire consisting of a 5 -point Likert scale. ${ }^{20}$ Patients also answered questions about demographics and whether an antibiotic was prescribed.

\section{Analysis}

Data were analyzed using SPSS 12.0 software (SPSS Inc, Chicago, Ill). Patient expectations were described using frequency distributions and dichotomized into a group combining the ratings "very important" and "rather important" and another group combining "a little important" and "not important." Differences in other desires between patients who hoped to receive a prescription for an antibiotic and those who did not were analyzed by using Pearson $\chi^{2}$ tests with continuity correction at a 5\% significance level. A multivariate logistic regression model was developed to test the independent predictors of the hope for an antibiotic by adjusting for possible confounding factors. All reasons for an encounter with a $P<.2$ in bivariate analysis were entered in the model as independent predictors. Patient's age, sex, educational background, self-perceived illness severity, belief in antibiotics to speed recovery from sore throat, and antibiotic prescription were included as possible confounders. The enter method was used and checked for robustness by forward and backward Wald methods. Two-tailed $t$ tests were used to compare means, and $P$ values $\leq .05$ were considered significant.

The study protocol was approved by the ethics committee of the Ghent University Hospital.

\section{RESULTS}

A total of 298 questionnaires were completed by patients visiting 68 family physicians. The mean number of patients per family physician was 4.4 (range 1-9). The mean age of the respondents was 36.7 (SD 15.8 ) years, $40.9 \%$ were male, $54.7 \%$ were employed, $31.8 \%$ had completed higher education (9 to 12 years after primary school), 32.6\% had completed 3 years of secondary education, $7.4 \%$ had only primary education, and $28.2 \%$ were students. Most (84.4\%) patients reported having a "throat infection," and a similar proportion $(86.5 \%)$ had a diagnosis as such by their family physician.

\section{What Do Patients Want?}

Reasons for visiting were ranked according to the number of patients endorsing an item as very/rather important. The 3 most highly endorsed reasons for a physician visit were an examination to establish the cause of the symptoms, to obtain pain relief, and to gain information on the course of the disease. More 
than $80 \%$ of all patients considered these 3 reasons very/rather important: "I want an antibiotic" ranked 11 th out of 13 items and was rated very/rather important by $37.6 \%$ of the respondents (very important by $16.3 \%$; Table 1$)$.

\section{Are Patients Who Want an Antibiotic Different?}

The ranking of the most important reasons for visiting the family physician was similar among those patients who hoped for an antibiotic $(\mathrm{n}=106)$ and those who did not ( $\mathrm{n}=176$; Table 1$)$. Patients who considered an antibiotic very/rather important, however, valued pain relief significantly more than patients who considered an antibiotic little/not important $\left(\chi^{2}=12.79_{i} P<.001\right)$. Patients who considered an antibiotic very/rather important also regarded the following items as more important compared with those who did not: receiving information about when they might recover, obtaining support for their problems, considering referral to a specialist, and obtaining a note for sick leave (Table 1). Patients who hoped for an antibiotic felt more severely ill (mean score on a 100-mm visual analogue scale 65.5 vs $\left.51.6_{i} t=4.397_{i} P<.001\right)$, had more faith in antibiotics to speed recovery $(P<.001)$, and were less convinced that acute sore throat is a self-limiting disease $(P<.012)$ and that frequent use of antibiotics is harmful for their own health $(P=.017)$ or a threat to public health $(P=.001)$. There were no notable or clinically significant differences between the 2 groups regarding age, sex, or educational background.

In bivariate analysis the desire for pain relief was the strongest predictor of the hope to receive an antibiotic prescription (crude odds ratio [OR], 7.56; 95\% confidence interval $[\mathrm{CI}], 2.25-25.35)$, followed by the patient's belief that antibiotics speed recovery from sore throat (crude OR, 4.02; 95\% CI, 2.18-7.41). In a multivariate model, adjusting for age, sex, educational status, self-perceived illness severity, belief in antibiotics to speed recovery from sore throat, antibiotic prescription, and other reasons for seeing the physician, the hope for pain relief remained a strong predictor (Table 2). Forward and backward logistic regression analyses produced similar results.

\section{Table 1. Importance of Different Reasons for Consulting the Family Physician With a Sore Throat in the Total Population and in the Subgroups of Patients Who Consider Antibiotics Very/Rather Important or Little/Not Important}

\begin{tabular}{|c|c|c|c|c|c|c|c|c|}
\hline \multirow[b]{2}{*}{ Reason for Visit } & \multicolumn{2}{|c|}{$\begin{array}{c}\text { Total } \\
\text { Population } \\
(n=298)\end{array}$} & \multicolumn{2}{|c|}{$\begin{array}{l}\text { Antibiotics } \\
\text { Very/Rather } \\
\text { Important } \\
(n=106)\end{array}$} & \multicolumn{2}{|c|}{$\begin{array}{l}\text { Antibiotics } \\
\text { Little/Not } \\
\text { Important } \\
(n=176)\end{array}$} & \multirow{2}{*}{$\begin{array}{l}\text { OR } \\
(95 \% \mathrm{Cl})\end{array}$} & \multirow{2}{*}{$\begin{array}{l}P \\
\text { Value* }\end{array}$} \\
\hline & $\%$ & $\mathbf{R}$ & $\%$ & $\mathbf{R}$ & $\%$ & $\mathbf{R}$ & & \\
\hline $\begin{array}{l}\text { I want to be examined for the cause of my } \\
\text { sore throat }\end{array}$ & 85.5 & 1 & 90.5 & 2 & 83.0 & 2 & $\begin{array}{l}1.95 \\
(0.91-4.18)\end{array}$ & .117 \\
\hline I want $\mathrm{Dr}$ to give me something for the pain & 84.5 & 2 & 97.1 & 1 & 81.8 & 3 & $\begin{array}{c}7.56 \\
(2.25-25.35)\end{array}$ & $<.001$ \\
\hline $\begin{array}{l}\text { I want Dr to explain the likely course of my } \\
\text { problem }\end{array}$ & 82.7 & 3 & 79.8 & 4 & 84.4 & 1 & $\begin{array}{c}0.73 \\
(0.39-1.37)\end{array}$ & .417 \\
\hline I want Dr to explain how serious my problem is & 76.4 & 4 & 79.0 & 5 & 75.0 & 5 & $\begin{array}{c}1.26 \\
(0.70-2.25)\end{array}$ & .529 \\
\hline I want to know how soon I will recover & 75.7 & 5 & 82.7 & 3 & 70.9 & 6 & $\begin{array}{c}1.97 \\
(1.08-3.59)\end{array}$ & .038 \\
\hline I want Dr to explain possible treatments & 73.2 & 6 & 69.5 & 6 & 75.4 & 4 & $\begin{array}{c}0.74 \\
(0.43-1.28)\end{array}$ & .347 \\
\hline I want Dr to talk with me about my sore throat & 57.5 & 7 & 61.5 & 7 & 55.7 & 7 & $\begin{array}{c}1.27 \\
(0.77-2.09)\end{array}$ & .412 \\
\hline I feel anxious and would like Dr's help & 53.2 & 8 & 60.2 & 8 & 49.7 & 8 & $\begin{array}{c}1.53 \\
(0.93-2.51)\end{array}$ & .117 \\
\hline I want Dr to talk to me about my worries & 49.6 & 9 & 51.0 & 10 & 49.1 & 9 & $\begin{array}{c}1.08 \\
(0.66-1.75)\end{array}$ & .865 \\
\hline I want a note for sick leave for school or work & 39.9 & 10 & 53.5 & 9 & 31.0 & 10 & $\begin{array}{l}2.56 \\
(1.54-4.25)\end{array}$ & $<.001$ \\
\hline I want an antibiotic & 37.6 & 11 & NA & NA & NA & NA & NA & NA \\
\hline I want to be referred to a specialist & 21.2 & 12 & 30.0 & 11 & 16.6 & 11 & $\begin{array}{c}2.16 \\
(1.20-3.87)\end{array}$ & .014 \\
\hline I have problems and seek support & 18.4 & 13 & 27.2 & 12 & 13.4 & 12 & $\begin{array}{l}2.42 \\
(1.30-4.48)\end{array}$ & .007 \\
\hline
\end{tabular}




\begin{tabular}{|lcc|}
\hline \multicolumn{3}{|l}{ Table 2. Multivariate Logistic Regression Model With Variables } \\
Associated With the Patient's Hope for Antibiotics, Adjusted \\
for Other Independent Predictors and Potential Confounders \\
\hline Variable & $\begin{array}{c}\text { Adjusted OR } \\
\mathbf{( 9 5 \% ~ C l ) *}\end{array}$ & P Value \\
\hline I want to be examined for the cause of my & $2.45(0.81-7.44)$ & .11 \\
sore throat & $6.44(1.16-35.73)$ & .03 \\
I want Dr to give me something for the pain & $1.21(0.50-2.95)$ & .68 \\
I want to know how soon I will recover & $0.65(0.28-1.52)$ & .32 \\
I feel anxious and would like Dr's help & $4.20(1.82-9.68)$ & .001 \\
I want a note for sick leave for school or work & $4.44(1.48-13.27)$ & .008 \\
I want to be referred to a specialist & $1.03(0.32-3.27)$ & .96 \\
I have problems and seek support & $1.00(0.99-1.02)$ & .64 \\
Patient's perceived illness severity & $4.03(1.71-9.50)$ & .001 \\
Patient received an antibiotic prescription & $1.01(0.98-1.04)$ & .34 \\
Age of patient & $0.60(0.28-1.29)$ & .19 \\
Male patient & $1.01(0.87-1.16)$ & .91 \\
Educational level of patient & $3.52(1.44-8.57)$ & .006 \\
"Antibiotics speed recovery from sore throat" & & \\
\hline OR = odds ratio; CI = confidence interval. & & \\
* Adjusted for all variables mentioned in the table. & & \\
\hline
\end{tabular}

\section{DISCUSSION}

We found that pain relief was an important concern of patients with an acute sore throat who visited their family physician. Moreover, patients who hoped to receive a prescription for an antibiotic were even more concerned about pain relief compared with patients who considered an antibiotic little/not important. The relationship between importance of pain relief and the wish for an antibiotic was even stronger than the expected relationship with the patient's belief in antibiotics to speed recovery, and this relationship remained, even when adjusting for other factors (eg, self-assessed illness severity, antibiotic prescription, belief in antibiotics, and need to legitimize the illness episode). This finding indicates that adequate analgesia may be a more important reason for seeking medical care than receiving an antibiotic, and suggests that patients who hope for an antibiotic may, in fact, want a treatment to alleviate pain. Indeed, they may believe that antibiotics are the best treatment for pain in acute sore throat.

A limitation of our study is the use of a postvisit questionnaire. The patient's expectations may have been influenced by what happened during the physician visit. Our data showed such could be the case for antibiotics, as patients who strongly valued an antibiotic were more likely to receive a prescription for an antibiotic. Including this variable in the regression model, however, did not substantially change our findings. Patients' hope for pain relief remained the strongest predictor of hoping for an antibiotic. Other research using both pre- and postvisit questionnaires has shown that patients' opinions and perceptions do not change significantly during the visit. ${ }^{14,21}$ As patients were recruited by their family physicians, it is possible that not all patients complaining of a sore throat were included and that family physicians selected better educated patients who are more able to understand the questionnaire. We would expect these patients to have a better understanding of the limits and hazards linked to use of antibiotics. Even in this selected group, we find a strong association between hope for antibiotics and treatment of pain. This finding implies that we could expect this association to be even stronger in a population of patients who are less aware of the limited effectiveness and the hazards of antibiotics. The selected patients may have been less severely ill and therefore less likely to receive an antibiotic prescription. A previous study in the same region did not find an important bias through noninclusion with regard to clinical features. ${ }^{22}$ In our study, this selection would actually be desirable, because all guidelines recommend antibiotic treatment in severely ill patients. ${ }^{1-4}$ The question of whether to prescribe antibiotics is most relevant in (most) patients with acute sore throat who are not very ill or unlikely to have a streptococcal infection.

We limited our study to patients with an acute sore throat for 2 reasons. Firstly, an evidence-based guideline on the management of acute sore throat was available to guide physicians, ${ }^{4}$ but guideline adoption was not widespread. Second, acute sore throat differs from other acute upper respiratory tract infections with regard to symptoms and their impact on the patient's daily life. As a result, even though the findings of our study are applicable to primary care patients complaining of a sore throat, they should not be generalized to all acute respiratory tract infections.

Other authors have reported on expectations of patients with upper respiratory tract infections in general. ${ }^{8,10,14}$ Qualitative research has pointed to the importance of reassurance, information, and pain relief in acute sore throat. ${ }^{9}$ To our knowledge, the desire for pain and symptom relief has been quantified in only 2 cross-sectional surveys of patients with symptoms of respiratory tract infections. ${ }^{23,24}$ Data on sore throat are not reported separately, but both studies point at a link between (sinus) pain and the patient's perspective of the need for antibiotics.

Clinical trials of different treatments for acute sore throat often use symptom resolution as an outcome. 
This composite endpoint includes pain. Antibiotics have been shown to be effective in (slightly) shortening the duration of symptoms, ${ }^{25}$ but an effect on the intensity of pain is not generally reported. If we recommend analgesic treatment, we need evidence that such treatment is efficacious. We found only 7 trials that assess the efficacy of over-the-counter analgesics compared with placebo and only 1 comparing nonsteroidal antiinflammatory drugs with paracetamol. ${ }^{26}$ We have been unable to identify any trials that compare antibiotic treatment with an adequate analgesic regimen.

Evidence-based practice guidelines on the management of acute sore throat focus on whether to prescribe an antibiotic. Pain relief is usually mentioned as an option in the general management of sore throat, ${ }^{1-4}$ but in clinical practice this issue receives secondary attention. Concerns about poor implementation of evidence-based guidelines on sore throat focus on antibiotic prescribing. Successful adoption of evidence-based medicine in practice requires attention to broader issues, including understanding and addressing the patient's concerns, ${ }^{27}$ which is also a general principle of good clinical practice. Family practice research should aim to bridge the gap between biomedical evidence (antibiotics or not) and contextual evidence (the patient's pain). ${ }^{27,28}$ Our study suggests that the patient's desire for an antibiotic may be based on the mistaken view that this treatment is best for pain relief. When patients feel ill and experience pain, their main concern might be to obtain alleviation for their symptoms, and so they expect strong medication such as an antibiotic. These findings however, need to be confirmed in other studies. To strengthen the evidence base for nonantibiotic management of acute sore throat, we need studies comparing antibiotic treatment with optimum analgesia. It would be interesting to find out whether exploring patients' expectations about treatment for pain and offering adequate analgesic treatment can assist physicians in the management of sore throats more often without prescribing antibiotics. This hypothesis needs to be tested in a trial before we can make recommendations to change clinical practice.

To read or post commentaries in response to this article, see it online at http://www.annfammed.org/cgi/content/full/4/6/494.

Key words: Anti-bacterial agents; prescriptions; family practice; physician's practice patterns; physician-patient relations; patient expectations; respiratory tract infections; evidence-based medicine

Submitted February 16, 2006; submitted, revised, April 30, 2006; accepted, May 23, 2006.

Versions of this article were presented at the WONCA Europe Regional Conference, Amsterdam, The Netherlands, June 1-4, 2004; and the International Conference on Communication in Healthcare (EACH), Bruges, Belgium, September 14-17, 2004.
Funding support: This research project was supported by a grant from the Belgian Federal Science Policy Office. The funding source had no involvement in the study or interpretation of the results.

Acknowledgments: We wish to thank all the physicians and patients who participated in our study and Siegfried Provoost and Tom Van Paepegem for their contributions in performing the study.

\section{References}

1. Snow V, Mottur-Pilson C, Cooper RJ, Hoffman JR. Principles of appropriate antibiotic use for acute pharyngitis in adults. Ann Intern Med. 2001;134:506-508.

2. Department of Health. Prodigy knowledge. Prodigy guidance: sore throat - acute. Available at: http://www.prodigy.nhs.uk/guidance. asp?gt=Sore\%20throat\%20-\%20acute.

3. The Dutch College of General Practitioners (NHG). The Dutch College of General Practitioners (NHG) Practice Guideline Acute sore throat. Available at: http://nhg.artsennet.nl/upload/104/guidelines2/E11.htm.

4. Belgian Antibiotic Policy Coordination Committee. Guideline: acute sore throat [Dutch]. BAPCOC. 2001. Available at: http://www.health. fgov.be/antibiotics/ndl/antibiotica-homepage.htm.

5. Goossens H, Ferech M, Vander Stichele R, Elseviers M. Outpatient antibiotic use in Europe and association with resistance: a crossnational database study. Lancet. 2005;365:579-587.

6. Van der Heyden J, Jonckheer P, Bastiaens H, LaFontaine M-F, Van Casteren V. Quality improvement in general practice based on registration of practice data: diabetes type 2 and acute sore throat [Dutch]. Belgian Scientific Institute of Public Health; 2000. IPH/EPI Reports No. 2000-013.

7. De Sutter AI, De Meyere MJ, De Maeseneer JM, Peersman WP. Antibiotic prescribing in acute infections of the nose or sinuses: a matter of personal habit? Fam Pract. 2001;18:209-213.

8. Macfarlane J, Holmes W, Macfarlane R, Britten N. Influence of patients' expectations on antibiotic management of acute lower respiratory tract illness in general practice: questionnaire study. BMJ. 1997;315:1211-1214.

9. Butler CC, Rollnick S, Pill R, Maggs-Rapport F, Stott N. Understanding the culture of prescribing: qualitative study of general practitioners' and patients' perceptions of antibiotics for sore throats. BMJ. 1998;317:637-642.

10. Dosh SA, Hickner JM, Mainous AG, 3rd, Ebell MH. Predictors of antibiotic prescribing for nonspecific upper respiratory infections, acute bronchitis, and acute sinusitis. An UPRNet study. Upper Peninsula Research Network. J Fam Pract. 2000;49:407-414.

11. Little P, Dorward M, Warner G, et al. Importance of patient pressure and perceived pressure and perceived medical need for investigations, referral, and prescribing in primary care: nested observational study. BMJ. 2004;328:444-447.

12. Barry CA, Bradley CP, Britten N, Stevenson FA, Barber N. Patients' unvoiced agendas in general practice consultations: qualitative study. BMJ. 2000;320:1246-1250.

13. Rollnick $S$, Seale $C$, Rees $M$, et al. Inside the routine general practice consultation: an observational study of consultations for sore throats. Fam Pract. 2001;18:506-510.

14. Hamm RM, Hicks RJ, Bemben DA. Antibiotics and respiratory infections: are patients more satisfied when expectations are met? J Fam Pract. 1996;43:56-62.

15. Britten $N$, Ukoumunne $\mathrm{O}$. The influence of patients' hopes of receiving a prescription on doctors' perceptions and the decision to prescribe: a questionnaire survey. BMJ. 1997;315:1506-1510.

16. Himmel W, Lippert-Urbanke E, Kochen MM. Are patients more satisfied when they receive a prescription? The effect of patient expectations in general practice. Scand J Prim Health Care. 1997;15:118-122. 
17. Cockburn J, Pit S. Prescribing behaviour in clinical practice: patients' expectations and doctors' perceptions of patients' expectations-a questionnaire study. BMJ. 1997;315:520-523.

18. Valori R, Woloshynowych M, Bellenger N, Aluvihare V, Salmon P. The Patient Requests Form: a way of measuring what patients want from their general practitioner. J Psychosom Res. 1996;40:87-94.

19. Van den Brink-Muinen A, Bensing J, Verhaak P. The Eurocommunication Study, An International Comparative Study in Six European Countries on Doctor-Patient Communication in General Practice. Utrecht: Nivel; 2003.

20. van Duijn $\mathrm{H}$, Kuyvenhoven $\mathrm{M}$, Welschen I, et al. Patients' and doctors' views on respiratory tract symptoms. Scand J Prim Health Care. 2002;20:201-202.

21. Deveugele M, Derese A, De Maeseneer J. Is GP-patient communication related to their perceptions of illness severity, coping and social support? Soc Sci Med. 2002;55:1245-1253.

22. De Sutter AI, De Meyere MJ, Christiaens TC, et al. Does amoxicillin improve outcomes in patients with purulent rhinorrhea? A pragmatic randomized double-blind controlled trial in family practice. J Fam Pract. 2002;51:317-323.
23. Ray DA, Rohren $\mathrm{CH}$. Characteristics of patients with upper respiratory tract infection presenting to a walk-in clinic. Mayo Clin Proc. 2001;76:169-173.

24. Linder JA, Singer DE. Desire for antibiotics and antibiotic prescribing for adults with upper respiratory tract infections. J Gen Intern Med. 2003;18:795-801.

25. Del Mar CB, Glasziou PP, Spinks AB. Antibiotics for sore throat. Cochrane Database Syst Rev. 2005:CD000023.

26. Lala I, Leech P, Montgomery L, Bhagat K. Use of a simple pain model to evaluate analgesic activity of ibuprofen versus paracetamol. East Afr Med J. 2000;77:504-507.

27. De Maeseneer JM, van Driel ML, Green LA, van Weel C. The need for research in primary care. Lancet. 2003;362:1314-1319.

28. van Weel C, Rosser WW. Improving health care globally: a critical review of the necessity of family medicine research and recommendations to build research capacity. Ann Fam Med. 2004;2(Suppl 2): S5-S16.

\section{Annals of Family Medicine Resident Research Supplement Call for Papers and Reviewers}

The Annals of Family Medicine seeks both research manuscripts and peer reviewers for a supplement devoted to research conducted by family medicine residents. The supplement is sponsored by the American Academy of Family Physicians Foundation.

Volunteer Reviewers. We encourage residents, residency faculty members, and others interested in nurturing resident research to contribute by reviewing 1 to 2 resident manuscripts in their areas of interest and expertise. To volunteer, please e-mail ressupp@musc.edu, giving your: (1) name; (2) role: resident, residency faculty member, or other ${ }_{i}(3)$ methods expertise: quantitative and/or qualitative methods; and (4) interest in reviewing manuscripts on clinical, quality improvement, community, health services, educational, or other research. We will send instructions on how to conduct a helpful peer review.

Submit Manuscripts. Manuscripts must be based on original work conducted while the lead author is/was a resident in a family medicine training program. They must describe original research that contributes new, transportable knowledge (excluding case reports, nonsystematic reviews, or essays). Manuscripts must follow the instructions for authors, available at http://annfammed.org/misc/ifora.shtml. The deadline for submission of manuscripts is March 1, 2007. Those submitted earlier will have priority in the review process.

Submit manuscripts to: ressupp@musc.edu.

Do not submit manuscripts for this supplement directly to the Annals.

Review Process. Guest editors Peter J. Carek, MD, MS, and Arch G. Mainous III, PhD, of the Medical University of South Carolina will coordinate initial peer review by reviewers who volunteer in response to this announcement. Based on this initial review, they will select manuscripts for formal peer review by the Annals. We will invite authors of the selected papers to submit a revised manuscript for possible inclusion in the supplement. The anticipated publication date of the supplement is January 2008. 